\title{
The disease burden of chronic obstructive pulmonary disease in Greece
}

\author{
This article was published in the following Dove Press journal: \\ International Journal of COPD \\ 9 September 2016 \\ Number of times this article has been viewed
}

\author{
Georgia Kourlaba' \\ Georgios Hillas ${ }^{2}$ \\ Theodoros Vassilakopoulos ${ }^{2}$ \\ Nikos Maniadakis ${ }^{3}$ \\ 'Evroston LP, ${ }^{2}$ Department of \\ Critical Care of Evangelismos \\ Hospital, Medical School of \\ National \& Kapodistrian University \\ of Athens, ${ }^{3}$ Department of \\ Health Services Organization and \\ Management, National School of \\ Public Health, Athens, Greece
}

Background: The objective of the study was to estimate the self-reported prevalence of chronic obstructive pulmonary disease (COPD) in Greece and to quantify its burden on patients' daily activities, productivity, and psychological status.

Methods: A population-based, random digit-dialed telephone nationwide survey was conducted between July 10, 2015 and July 31, 2015 in order to recruit patients with COPD in Greece. Among the 11,471 persons contacted, 3,414 met the inclusion criterion of age $\geq 40$ years and completed the screening questions regarding COPD. Of the 362 subjects who reported that they had been diagnosed with COPD, 351 completed the survey. Data on demographic and lifestyle characteristics, comorbidities, disease history, perceived disease severity, breathlessness severity, symptoms severity, limitations in daily activities, psychological distress, and productivity were collected. All data were collected through the telephone interview method using a structured questionnaire.

Results: The overall self-reported COPD prevalence was 10.6\%. Among 351 participants, only $9 \%$ reported that they suffered from severe breathlessness. The mean COPD assessment test score was 19.0 , with $84 \%$ of participants having a COPD assessment test score $\geq 10$. As for the perceived severity of COPD, the majority of subjects considered that their respiratory condition was of moderate (34.2\%) or mild severity (33.9\%). Overall, the participants reported a significant impact of COPD on their daily life. For instance, $61.5 \%$ of them reported that their respiratory condition has affected their sports activities. Moreover, $73 \%$ of subjects considered that the health care system could do more for them than it actually does. Almost one-fourth of the participants reported that they had missed work during the past 12 months due to their respiratory symptoms, with the mean number of days lost being 10 .

Conclusion: This survey provides insightful data regarding the impact of COPD on Greek patients' everyday life, psychology, and productivity, revealing the increased individual morbidity and the significant burden of this condition on society.

Keywords: COPD, impact, prevalence, morbidity, Greece

\section{Introduction}

Chronic obstructive pulmonary disease (COPD) is a leading cause of disability and death worldwide, with prevalence rates ranging between $5 \%$ and $13 \% .{ }^{1}$ Its prevalence is directly related to tobacco smoking and indoor air pollution and hence is expected to rise as smoking rates continue to increase. COPD was the third most frequent cause of death in 2012 as per the World Health Organization ${ }^{2}$ report and by 2020 it is predicted to become the fifth most common cause of disability. ${ }^{3}$

COPD is characterized by a progressive decline in lung function and health-related quality of life. ${ }^{4}$ Many studies have reported that COPD imposes a significant burden on individuals, the society, and the economy. ${ }^{5-8}$ In particular, there is abundant evidence
Correspondence: Georgia Kourlaba EVROSTON LP, Chatzigianni Mexi 5,

115 28, Athens, Greece

$\mathrm{Tel}+30216900$ I70I

$\mathrm{Fax}+302169001702$

Email g.kourlaba@evroston.com
International Journal of COPD 2016:1/ 2179-2।89 Dovepress f $y$ in 0 http://dx.doi.org// 0.21 477/COPD.SI I 0373 (c) (1) (8) 2016 Kourlaba et al. This work is published and licensed by Dove Medical Press Limited. The full terms of this license are available at https://www.dovepress.com/terms.php cc) ${ }_{\mathrm{BY}} \mathrm{NC}$ and incorporate the Creative Commons Attribution - Non Commercial (unported, v3.0) License (http://creativecommons.org/licenses/by-nc/3.0/). By accessing the work you hereby accept the Terms. Non-commercial uses of the work are permitted without any further permission from Dove Medical Press Limited, provided the work is properly attributed. For permission for commercial use of this work, please see paragraphs 4.2 and 5 of our Terms (https://www.dovepress.com/terms.php). 
demonstrating that COPD is associated with physical impairment, ${ }^{9}$ reduced work production, ${ }^{10}$ depression and anxiety, ${ }^{9}$ high rates of readmission to hospital, ${ }^{11}$ and death. ${ }^{12}$ It has also been suggested that the burden of symptom in patients with COPD is comparable to that of patients with cancer and is more durable as those with COPD live longer with the condition. ${ }^{13}$

In Greece, the prevalence of COPD has been estimated at $8.4 \%$ of the population aged $>35$ years with smoking history of at least 100 cigarettes per lifetime, in 2004. ${ }^{14}$ Prevalence was found to be higher in male (11.6\%) compared to female $(4.8 \%)$ and in the population aged $>70$ years (23\%). ${ }^{14}$ According to the Hellenic Thoracic Society, mild COPD was the most frequent expression $(57.4 \%$ mild, $25.3 \%$ moderate, and $16 \%$ severe), with $81.4 \%$ of COPD patients actually not knowing that they were suffering from the condition. ${ }^{14}$ However, this study used the definitions of COPD that were considered appropriate at that time. Thus, patients having $>15 \%$ improvement in forced expiratory volume in 1 second $\left(\mathrm{FEV}_{1}\right)$ compared to prebronchodilator $\mathrm{FEV}_{1}$ or post-bronchodilator improvement of $\mathrm{FEV}_{1}>200 \mathrm{~mL}$ were excluded and considered as asthmatics. It is now well established that many COPD patients exhibit positive bronchodilator responses and thus these criteria should not be used to exclude the diagnosis of COPD. The use of these criteria by Tzanakis et al unavoidably led to an underestimation of the true prevalence of COPD in the Greek population.

Despite the substantial impact that COPD seems to have on patients, health care systems, and economies, to the best of our knowledge, limited data are available regarding the COPD-related burden in Greece, while data regarding the impact of COPD on patients' daily activity, work, and psychological distress are completely lacking. In this context, the objective of the present work was to estimate the current self-reported prevalence of COPD in Greece, to quantify the burden of the disease on patients' daily living, work, and estimate patients' psychological distress.

\section{Materials and methods}

\section{Study design and population}

A population-based, random digit-dialed, telephone nationwide survey was conducted between July 10, 2015 and July 31, 2015 in order to recruit patients with COPD in Greece. A proportionate stratification by region systematic sampling procedure was used, in order to ensure a nationally representative sample of the urban/rural population, based on the distribution of population obtained from the census of 2011 (www.statistics.gr).
Sampling of 29,811 households with landline telephone was conducted, and respondents were interviewed by computer-assisted telephone interviewing (CATI). Of the 29,811 phone numbers, only 11,471 (38.5\%) were handled calls (conducted persons). The rest were rejected for various reasons (ie, no answer, busy, etc). Households were firstly screened for any persons aged $\geq 40$ years and thereafter, the age and sex of all household members aged $\geq 40$ years were recorded. These data were recorded for 3,429 households. Afterward, responders were asked whether any member (40+) of their household, including themselves, has been diagnosed with COPD or regularly use medication to treat this condition. Of the 3,429 households, 3,414 answered this question and COPD patients were reported to exist in 362 households. Of the 362 cases, eleven denied to participate in the study (response rate $=97 \%$ ) (Figure 1 ). In cases where the patient was unable to be interviewed, the questionnaire was completed with the aid of the caregiver (for 62 out of 351 participants). The sample size had been calculated as adequate in order to estimate an expected 9\% COPD prevalence with a precision of $1 \%$ at the $95 \%$ confidence level with a power of the study $>80 \%$.

Prior to the completion of the survey, all patients were informed of the purpose of the study, the confidentiality, and anonymity of the answers, and that they could terminate the interview at any time. Then, they provided verbal consent to participate. Ethical approval was not required by the IRB of National School of Public Health, because specific regulatory criteria listed elsewhere were met. ${ }^{5}$

\section{Data collection}

Telephone interviews were conducted using a structured questionnaire and had an average duration of 30 minutes. Most of the items in the questionnaire of the survey were based on the confronting COPD study questionnaire ${ }^{5}$ and notably validated patient-reported outcome instruments were used to elicit patient responses.

More specifically, the following data were recorded:

\section{Sociodemographic and anthropometric characteristics}

Sociodemographic and anthropometric characteristics such as age, sex, and self-reported weight and height based on which the body mass index (BMI) were calculated. Based on the BMI, patients were classified into three groups: normal weight (BMI $<25 \mathrm{~kg} / \mathrm{m}^{2}$ ), overweight (BMI 25-30 kg/m²), and obese (BMI $\left.>30 \mathrm{~kg} / \mathrm{m}^{2}\right)$. 


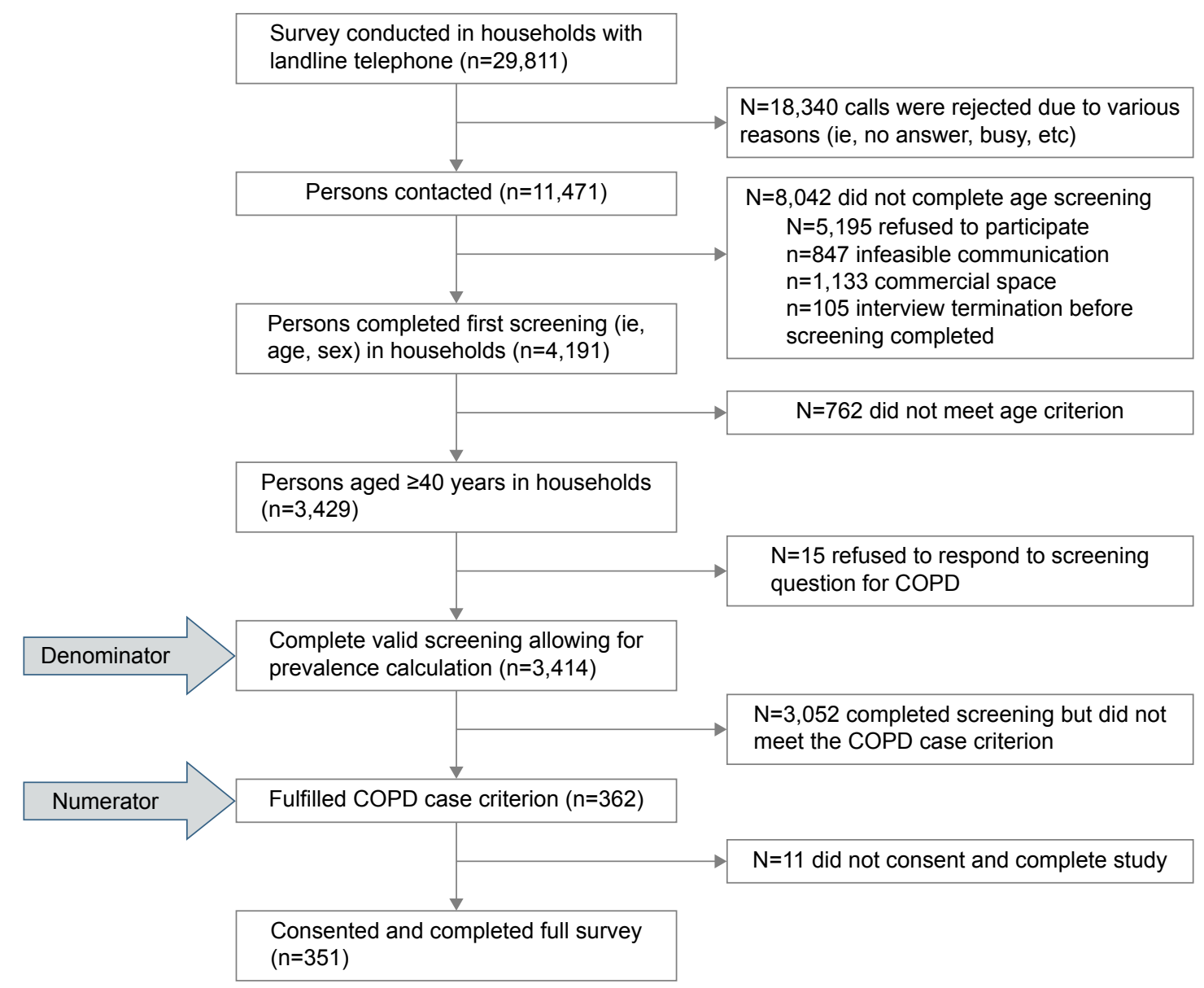

Figure I Sampling strategy of the survey.

Abbreviation: COPD, chronic obstructive pulmonary disease.

\section{Comorbidities and COPD history}

Participants were asked to report if they have been told by their physicians that they have asthma, hypertension, diabetes, myocardial infarction, heart failure, stroke, and cancer. Moreover, the duration since the time of COPD diagnosis was recorded.

\section{Smoking habits}

Participants' smoking status was recorded to be classified as current, ex-, and nonsmokers. Current smokers were defined as those who were presently smoking cigarettes/cigars/pipe at least once per day; ex-smokers, those who were not currently smoking, but who had smoked at least 100 cigarettes in their lifetime and at some point smoked on a daily basis; and nonsmokers as those who have smoked $<100$ cigarettes in their lifetime and are not currently smoking or never smoked at all. Additionally, the mean daily number of cigarettes or the time since cessation of smoking was reported by current and former smokers, respectively. All participants were further questioned about exposure to passive smoking, environmental smoke, dust, or fumes.

\section{Severity of breathlessness}

The modified Medical Research Council (mMRC) breathlessness scale was used. ${ }^{15}$ Subjects were asked to choose which of five statements (grades) best described their recent condition. Grades 0 and 1 indicated mild breathlessness, grades 2 and 3 moderate breathlessness, and grade 4 severe breathlessness.

\section{Symptom severity}

Overall symptom severity was assessed with the COPD assessment test (CAT) score. ${ }^{16,17}$ In addition, data on the subjects' overall perception of severity of COPD were also collected by asking the question: "Overall, how severe is your respiratory condition now?" with four proposed responses (mild, moderate, severe, and very severe).

\section{Disease exacerbations during the past 12 months}

The number of exacerbations was not explicitly documented, and the history of an exacerbation was indirectly determined by using three specific criteria published elsewhere: ${ }^{6}$ specifically, an exacerbation was considered to have occurred in 
the previous 12 months if the subject fulfilled any of the following criteria:

Criterion 1: In the last 12 months, have you been told by your physician that you have had worsening of your "respiratory condition"? - YES

Criterion 2: In the last 12 months, have you been told by your physician that you have had acute bronchitis? - YES

Criterion 3: In the last 12 months, what aspects of your "Respiratory Condition" have worsened? (cough during the daytime, cough during the night, phlegm, breathlessness or shortness of breath and fatigue, and ability to perform regular activities) - at least two symptoms cited.

\section{GOLD category}

On the basis of the CAT score and exacerbation history, participants were classified into one of the four groups (A-D) according to an adaptation of the 2011 Global initiative for chronic Obstructive Lung Disease (GOLD) classification, ${ }^{18}$ suggested in a previously published study. ${ }^{6}$

\section{Impact on work}

The impact of COPD on work was assessed using the following three questions:

1. In the past year, how many days of work have you missed due to COPD?

2. In the past year, how many days of work has a family member missed to take care of you?

3. In the past year, how many days of work did your health problem affect your ability to produce work output in a high-quality or timely manner?

\section{Impact of COPD on subjects' daily living activities}

A seven-item questionnaire was used to assess the impact of COPD on daily activities. In particular, the following question was asked:

How much do you feel that your respiratory condition limits what you can do in each of the following areas? Do you feel it restricts you a lot, some, only a little or not at all in: sports and recreation; normal physical exertion; social activities; sleeping; housekeeping chores; sexual intercourse; and family activities?

\section{Impact of COPD on psychological status}

The following question, with two possible response modalities (Yes and No), was used: Would you agree with each of the following statements?
- My cough or breathing is embarrassing me in public.

- I expect my condition to get worse.

- I panic or get afraid when I cannot get my breath.

- I feel that I am not in control of my breathing problem.

- I often worry about having an exacerbation (increase in severity of symptoms) when I am away from home.

- I have a hard time making plans because I never know how I will be feeling.

- The health care system could do a lot better job helping people with my condition.

\section{Statistical analysis}

Categorical variables were presented as absolute (n) and relative frequencies $(\%)$. Continuous variables were summarized as mean \pm standard deviation. The chi-square test, without the correction of continuity, was used in order to evaluate the associations between categorical variables. The Student's $t$-test or Mann-Whitney $U$-test was used to assess the association between a continuous variable (ie, age) and a binary variable (ie, CAT score $<10$ vs $\geq 10$ ), as appropriate. The one-way analysis of variance, after testing for equality of variances or the Kruskal-Wallis test, was used to evaluate the association between continuous variables (ie, age) and categorical variables with more than two groups (ie, GOLD category), as appropriate. Bonferroni correction was used to account for increase in type I error due to multiple comparisons. A probability value of 5\% was considered as statistically significant. All statistical calculations were performed using STATA software (version 8, 2003, StataCorp LP, College Station, TX, USA).

\section{Results}

\section{Self-reported prevalence and} sociodemographic, lifestyle and clinical characteristics

The overall COPD prevalence was found to be $10.6 \%$ (95\% confidence interval [CI]: 9.6\%-11.7\%). The prevalence of COPD was estimated to vary between $5.5 \%$ in rural areas and $13.6 \%$ in urban areas. Among the 351 participants with COPD, $54.1 \%$ were males and $41.3 \%$ were aged $>70$ years. Approximately $8 \%$ of participants were diagnosed with COPD during the previous year, with the mean time passed since COPD diagnosis being 9.4 years. The majority of participants were ex-smokers (38.8\%), followed by nonsmokers $(31.6 \%)$. Only $6 \%$ of the total sample of participants reported that they were free of comorbidities, with asthma being the most frequent comorbidity $(76.6 \%)$, followed by hypertension $(51.6 \%)$ and diabetes $(20.2 \%)$ (Table 1$)$. 
Table I Demographic and clinical characteristics of patients with COPD in Greece ( $\mathrm{N}=35 \mathrm{I})$

\begin{tabular}{|c|c|}
\hline Characteristics & n (\%) \\
\hline Sex (male) & $190(54.1)$ \\
\hline Age (years) & $65.8 \pm 12.8$ \\
\hline \multicolumn{2}{|l|}{ Geographic area } \\
\hline Urban & $293(84.4)$ \\
\hline Semiurban/rural & $54(15.6)$ \\
\hline \multicolumn{2}{|l|}{ BMI $\left(\mathrm{kg} / \mathrm{m}^{2}\right)$} \\
\hline$<25$ (underweight/normal weight) & $106(30.4)$ \\
\hline 25.0-29.9 (overweight) & $145(4 \mid .7)$ \\
\hline$\geq 30.0$ (obese) & $97(27.9)$ \\
\hline \multicolumn{2}{|l|}{ Self-reported comorbidities } \\
\hline No comorbidity & $21(6.0)$ \\
\hline Asthma & $269(76.6)$ \\
\hline Hypertension & $|8|(5 \mid .6)$ \\
\hline Diabetes mellitus & $7 \mid(20.2)$ \\
\hline \multicolumn{2}{|l|}{ COPD duration (years from diagnosis) } \\
\hline$<5$ & $135(38.5)$ \\
\hline $5-10$ & $104(29.6)$ \\
\hline$>10$ & III (3I.6) \\
\hline \multicolumn{2}{|l|}{ Smoking status } \\
\hline Current smoker & $103(29.3)$ \\
\hline Ex-smoker & $136(38.8)$ \\
\hline Nonsmoker & III (3I.6) \\
\hline \multicolumn{2}{|c|}{ Mean daily number of cigarettes (for current smokers) } \\
\hline$<10$ & $42(40.8)$ \\
\hline $10-19$ & $17(16.5)$ \\
\hline$\geq 20$ & $44(42.7)$ \\
\hline \multicolumn{2}{|l|}{$\begin{array}{l}\text { Time passed from the cessation of smoking } \\
\text { (for former smokers), years }\end{array}$} \\
\hline$\leq 5$ & $4 \mathrm{I}(30.8)$ \\
\hline $5-10$ & $42(31.6)$ \\
\hline$>10$ & $50(37.6)$ \\
\hline Passive smoking (yes) & $116 \pm 33.0$ \\
\hline $\begin{array}{l}\text { Live/work in a space with environmental } \\
\text { smoke/dust/fumes exposure (yes) }\end{array}$ & $30 \pm 8.6$ \\
\hline
\end{tabular}

Note: Data are presented as mean \pm standard deviation.

Abbreviations: BMI, body mass index; COPD, chronic obstructive pulmonary disease.

\section{Severity of breathlessness (mMRC), symptom severity (CAT), and exacerbation in the overall sample}

Overall, the "short of breath when hurrying on the level or walking up a slight incline" (Grade 2) was the most frequently reported grade of breathlessness (35\%). Almost 9\% of subjects reported the highest breathlessness grade (too breathless to leave the house). As for the perceived severity of COPD, the majority of COPD patients considered that their respiratory condition was moderate or mild (34.2\% and $33.9 \%$, respectively), with nearly one-quarter considering their respiratory condition as severe. The mean CAT score of participants was calculated to be 19.0 and as such, the vast majority of them were classified into the group of CAT score $\geq 10$ (84\%). Exacerbations during the past 12 months were detected in almost half of COPD patients (51.7\%). Moreover, almost half of the participants were classified into the GOLD category D (49.9\%), followed by GOLD category B (34.1\%) (Table 2).

\section{Perceived severity of COPD according to subjects' characteristics}

Perceived disease severity was assessed in terms of the subjects' demographics, CAT score, severity of breathlessness, history of exacerbations, and GOLD categories. The results are summarized in Table 3 . The perception of severity was not associated with BMI status, smoking habits, and comorbidities. Males were more likely to consider their symptoms as severe/very severe compared to females $(P<0.001)$. The percentage of participants who considered

Table 2 Symptoms severity and exacerbations in patients with COPD in Greece $(\mathrm{N}=35 \mathrm{I})$

\begin{tabular}{|c|c|}
\hline COPD symptoms severity and exacerbations & n (\%) \\
\hline \multicolumn{2}{|l|}{ mMRC grade } \\
\hline Mild breathlessness $(0-I)$ & $|7|(50.0)$ \\
\hline Moderate breathlessness (2-3) & $140(40.9)$ \\
\hline Severe breathlessness (4) & $31(9.1)$ \\
\hline \multicolumn{2}{|l|}{ CAT score } \\
\hline$<10$ & $54(16.0)$ \\
\hline$\geq 10$ & $284(84.0)$ \\
\hline \multicolumn{2}{|l|}{ Patients' perception of COPD severity } \\
\hline Mild & $119(33.9)$ \\
\hline Moderate & $120(34.2)$ \\
\hline Severe & $85(24.2)$ \\
\hline Very severe & $26(7.4)$ \\
\hline \multicolumn{2}{|l|}{ In the last 12 months, what aspects of your } \\
\hline \multicolumn{2}{|l|}{ "Respiratory condition" have worsened? } \\
\hline Cough during the daytime & $90(25.6)$ \\
\hline Cough during the night & $123(35.0)$ \\
\hline Phlegm & III (3I.7) \\
\hline Breathlessness or shortness of breath and fatigue & $148(42.5)$ \\
\hline Ability to perform regular activities & I 38 (39.4) \\
\hline At least two of the above symptoms & I5I (43.3) \\
\hline \multirow{2}{*}{\multicolumn{2}{|c|}{$\begin{array}{l}\text { In the last } 12 \text { months, have you been told } \\
\text { by your physician that: }\end{array}$}} \\
\hline & \\
\hline You have had worsening of your & $101(29.1)$ \\
\hline \multicolumn{2}{|l|}{ “Respiratory Condition?” (Y) } \\
\hline You have had acute bronchitis? (Y) & $103(29.6)$ \\
\hline \multicolumn{2}{|l|}{ GOLD category } \\
\hline$A$ & $48(14.2)$ \\
\hline B & II 5 (34.I) \\
\hline C & $6(1.8)$ \\
\hline $\mathrm{D}$ & 168 (49.9) \\
\hline \multicolumn{2}{|l|}{ Exacerbation during the last 12 months } \\
\hline Yes & $|8|(5 \mid .7)$ \\
\hline No & $169(48.3)$ \\
\hline
\end{tabular}

Abbreviations: CAT, COPD assessment test; COPD, chronic obstructive pulmonary disease; GOLD, Global initiative for chronic Obstructive Lung Disease; mMRC, modified Medical Research Council. 
Table 3 Perceived severity of COPD depending on patient characteristics and severity scores

\begin{tabular}{|c|c|c|c|c|}
\hline \multirow[t]{2}{*}{ Patients' characteristics } & \multicolumn{3}{|c|}{ Patients' perceived severity of COPD } & \multirow[t]{2}{*}{$\overline{P \text {-value }}$} \\
\hline & Very severe/severe (\%) & Moderate (\%) & Mild (\%) & \\
\hline Sex & & & & $<0.001$ \\
\hline Males & 42.4 & 29.6 & 28.0 & \\
\hline Females & 19.3 & 39.7 & 41.0 & \\
\hline Age group (years) & & & & $<0.001$ \\
\hline $40-49$ & 15.4 & 25.6 & 59.0 & \\
\hline $50-59$ & 13.7 & 30.0 & 56.3 & \\
\hline $60-69$ & 30.2 & 38.4 & 31.4 & \\
\hline$>70$ & 46.9 & 36.5 & 16.6 & \\
\hline BMI group & & & & 0.117 \\
\hline Underweight/normal weight & 26.7 & 33.3 & 40.0 & \\
\hline Overweight & 37.2 & 29.0 & 33.8 & \\
\hline Obese & 28.9 & 42.3 & 28.8 & \\
\hline Smoking status & & & & 0.127 \\
\hline Current smoker & 27.2 & 35.9 & 36.9 & \\
\hline Ex-smoker & 40.0 & 31.8 & 28.2 & \\
\hline Nonsmoker & 26.1 & 36.1 & 37.8 & \\
\hline Passive smoking & & & & 0.610 \\
\hline Yes & 27.8 & 38.3 & 33.9 & \\
\hline No & 32.7 & 31.9 & 35.4 & \\
\hline Environmental smoke & & & & 0.230 \\
\hline Yes & 16.6 & 33.4 & 50.0 & \\
\hline No & 34.1 & 34.1 & 32.8 & \\
\hline Comorbidities & & & & 0.314 \\
\hline Any comorbidity & 31.3 & 35.3 & 33.4 & \\
\hline No comorbidity & 38.1 & 19.0 & 42.9 & \\
\hline COPD + asthma & & & & 0.140 \\
\hline No & 40.2 & 30.5 & 29.3 & \\
\hline Yes & 29.2 & 35.4 & 35.4 & \\
\hline Years passed since COPD diagnosis & & & & 0.001 \\
\hline$<5$ years from diagnosis & 19.4 & 38.0 & 42.6 & \\
\hline $5-10$ years from diagnosis & 39.4 & 27.9 & 32.7 & \\
\hline$>10$ years from diagnosis & 39.6 & 35.2 & 25.2 & \\
\hline CAT score & & & & $<0.001$ \\
\hline$<10$ & 3.7 & 5.6 & 90.7 & \\
\hline$\geq 10$ & 36.4 & 40.3 & 23.3 & \\
\hline mMRC grade & & & & $<0.001$ \\
\hline Mild breathlessness $(0-1)$ & 17.5 & 31.6 & 50.9 & \\
\hline Moderate breathlessness (2-3) & 39.5 & 43.2 & 17.3 & \\
\hline Severe breathlessness (4) & 80.6 & 12.9 & 6.5 & \\
\hline Exacerbations during the past & & & & $<0.001$ \\
\hline \multicolumn{5}{|l|}{12 months } \\
\hline No exacerbation & 14.9 & 30.3 & 54.8 & \\
\hline Exacerbation & 47.5 & 37.6 & 14.9 & \\
\hline GOLD category ${ }^{a}$ & & & & $<0.001$ \\
\hline A & 4.2 & 4.2 & 91.6 & \\
\hline B & 19.3 & 42.1 & 38.6 & \\
\hline$D$ & 48.2 & 38.7 & 13.1 & \\
\hline
\end{tabular}

Notes: a Only six patients were in GOLD category C, and therefore were excluded. Bold indicates the statistically significant results at a level of $5 \%$.

Abbreviations: BMI, body mass index; CAT, COPD assessment test; GOLD, Global initiative for chronic Obstructive Lung Disease; COPD, chronic obstructive pulmonary disease; mMRC, modified Medical Research Council.

their symptoms severe/very severe was found to increase with age $(P<0.001)$ and the years passed since the time of COPD diagnosis $(P<0.001)$. Finally, participants were more likely to consider their symptoms being severe/very severe if they had experienced exacerbations during the past 12 months $(P<0.001)$, had severe breathlessness $(P<0.001)$, CAT score $\geq 10$, and were classified into GOLD category D $(P<0.001)$ (Table 3). 


\section{Impact of COPD on work}

Overall, 98 subjects out of 351 COPD patients who participated in the study $(27.9 \%)$ reported that they were currently employed. Among those, almost one-fourth reported having missed work completely during the past 12 months due to their respiratory symptoms, with the mean number of days lost being $10( \pm 23)$. In addition, $40 \%$ of participants reported that they were limited in the kind or amount of work that they could do for a mean number of $8( \pm 10)$ days. Finally, 39 of 351 COPD participants (11.1\%) reported that their respiratory condition has caused another member of their household to miss work at least once in the previous year.

The proportion of subjects reporting missed working days during the previous year was significantly greater in the highest GOLD category $(41.2 \%, P<0.001)$, in those who reported that they had experienced an exacerbation of their respiratory symptoms during the previous year (42.9\%, $P<0.001)$, and in subjects aged $60-69$ years $(50.0 \%$, $P=0.013)$. Similar results were detected with respect to work impairment (Table 4).

\section{The impact of COPD on subjects' daily activities and psychological status}

Overall, COPD patients reported that their respiratory condition was causing limitations in performing all the daily activities considered in the study. More specifically, the proportion of participants reporting some or a lot of limitation ranged from $28 \%$ to $61.5 \%$ with regard to sexual intercourse and sports activities (Figure 2).

Table 4 The association of COPD patients' characteristics with the impact of their respiratory condition on work

\begin{tabular}{|c|c|c|c|c|c|c|}
\hline \multirow[t]{2}{*}{ Patients' characteristics } & \multicolumn{3}{|c|}{$\begin{array}{l}\text { In the past year, did you miss any } \\
\text { days of work due to COPD? }\end{array}$} & \multicolumn{3}{|c|}{$\begin{array}{l}\text { Did your health problem affect your } \\
\text { ability to produce work output in a } \\
\text { high-quality or timely manner? }\end{array}$} \\
\hline & Yes (\%) & No (\%) & $P$-value & Yes (\%) & No (\%) & $P$-value \\
\hline Sex & & & 0.348 & & & 0.013 \\
\hline Males & 19.8 & 70.2 & & 52.7 & 47.3 & \\
\hline Females & 19.5 & 80.5 & & 26.8 & 73.2 & \\
\hline Age group (years) & & & 0.020 & & & 0.578 \\
\hline $40-49$ & 27.6 & 72.4 & & 44.8 & 55.2 & \\
\hline $50-59$ & 15.7 & 84.3 & & 36.7 & 63.3 & \\
\hline $60-69$ & 50.0 & 50.0 & & 50.0 & 50.0 & \\
\hline BMI group & & & 0.799 & & & 0.900 \\
\hline Underweight/normal weight & 25.8 & 74.2 & & 45.2 & 54.8 & \\
\hline Overweight & 28.6 & 71.4 & & 39.0 & 61.0 & \\
\hline Obese & 20.0 & 80.0 & & 41.7 & 58.3 & \\
\hline Smoking status & & & 0.953 & & & 0.022 \\
\hline Current smoker & 27.7 & 72.3 & & 39.1 & 60.9 & \\
\hline Ex-smoker & 23.5 & 76.5 & & 57.6 & 42.4 & \\
\hline Nonsmoker & 23.5 & 76.5 & & 17.7 & 82.4 & \\
\hline Exacerbations during the last 12 months & & & 0.007 & & & 0.001 \\
\hline No exacerbation & 15.9 & 84.1 & & 29.0 & 71.0 & \\
\hline Exacerbation & 42.9 & 57.1 & & 64.7 & 35.3 & \\
\hline Comorbidities & & & 0.999 & & & 0.397 \\
\hline Any comorbidity & 25.8 & 74.2 & & 42.9 & 57.1 & \\
\hline No comorbidity & 20.0 & 80.0 & & 20.0 & 80.0 & \\
\hline Asthma + COPD & & & 0.368 & & & 0.144 \\
\hline No & 16.7 & 83.3 & & 16.7 & 83.3 & \\
\hline Yes & 29.1 & 70.9 & & 45.2 & 54.8 & \\
\hline Years passed since COPD diagnosis & & & 0.651 & & & 0.895 \\
\hline$<5$ years since diagnosis & 24.0 & 76.0 & & 39.6 & 60.4 & \\
\hline $5-10$ years since diagnosis & 20.8 & 79.2 & & 45.8 & 54.2 & \\
\hline$>10$ years since diagnosis & 33.3 & 66.7 & & 41.7 & 58.3 & \\
\hline GOLD categorya & & & 0.029 & & & $<0.001$ \\
\hline A & 13.0 & 87.0 & & 9.1 & 90.9 & \\
\hline B & 17.5 & 82.5 & & 40.0 & 60.0 & \\
\hline D & 41.2 & 58.8 & & 66.7 & 33.3 & \\
\hline
\end{tabular}

Notes: aThere were only six patients in GOLD category C, and therefore were excluded. Bold indicates the statistically significant results at a level of $5 \%$. Abbreviations: BMI, body mass index; COPD, chronic obstructive pulmonary disease; GOLD, Global initiative for chronic Obstructive Lung Disease. 


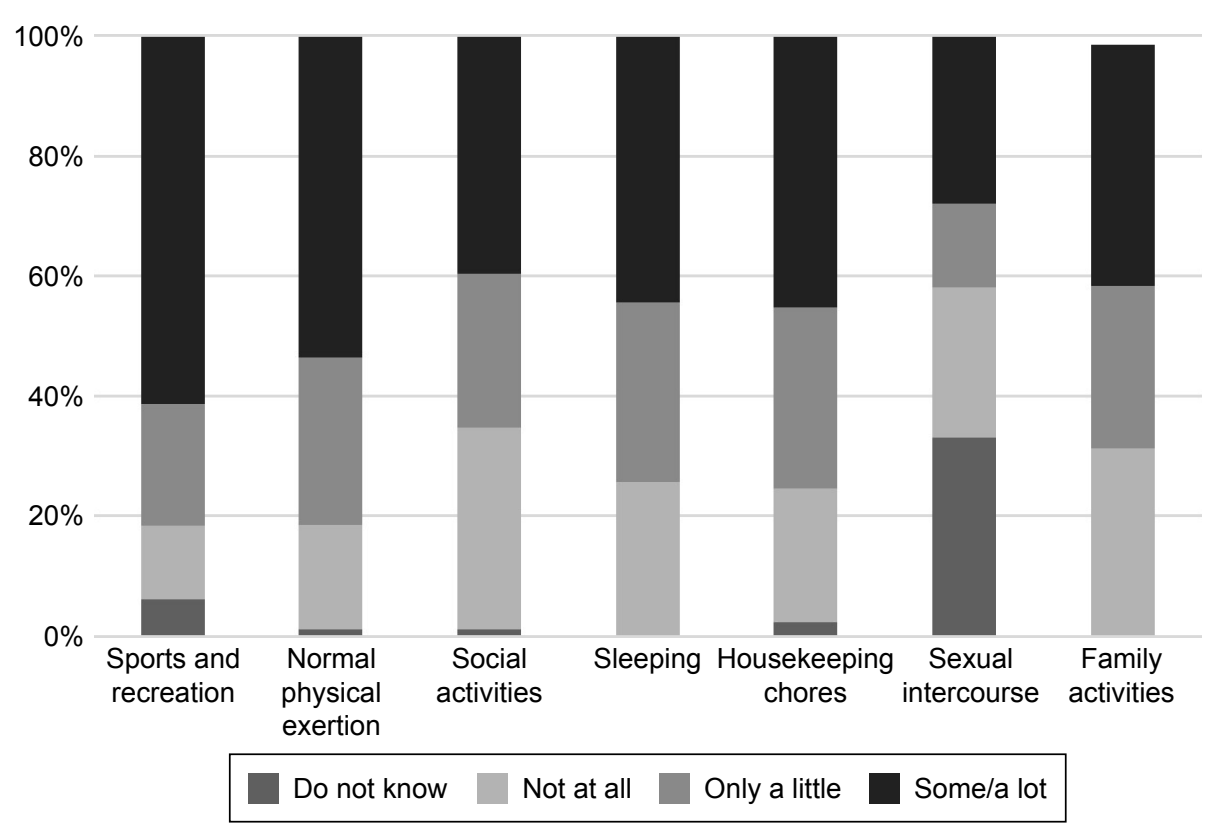

Figure $\mathbf{2}$ The impact of COPD on patients' daily activities in Greece. Abbreviation: COPD, chronic obstructive pulmonary disease.

The impact of symptoms on a number of psychological parameters related to anxiety and distress is reported in Figure 3. Many patients often worry about having an exacerbation, panic/get afraid when they cannot get their breath, expecting their condition to worsen, and feel embarrassed because of their condition in the public, while they consider that the health care system could do more for them than it actually does (Figure 3).

\section{Discussion}

The current study is a population-based, nationwide telephone survey that sought to estimate the self-reported prevalence and burden of COPD in Greece. The survey included patients aged $\geq 40$ years with physician-diagnosed COPD. This is the first study in Greece aiming to evaluate the impact of COPD on patients' daily activities, psychological distress, and work.

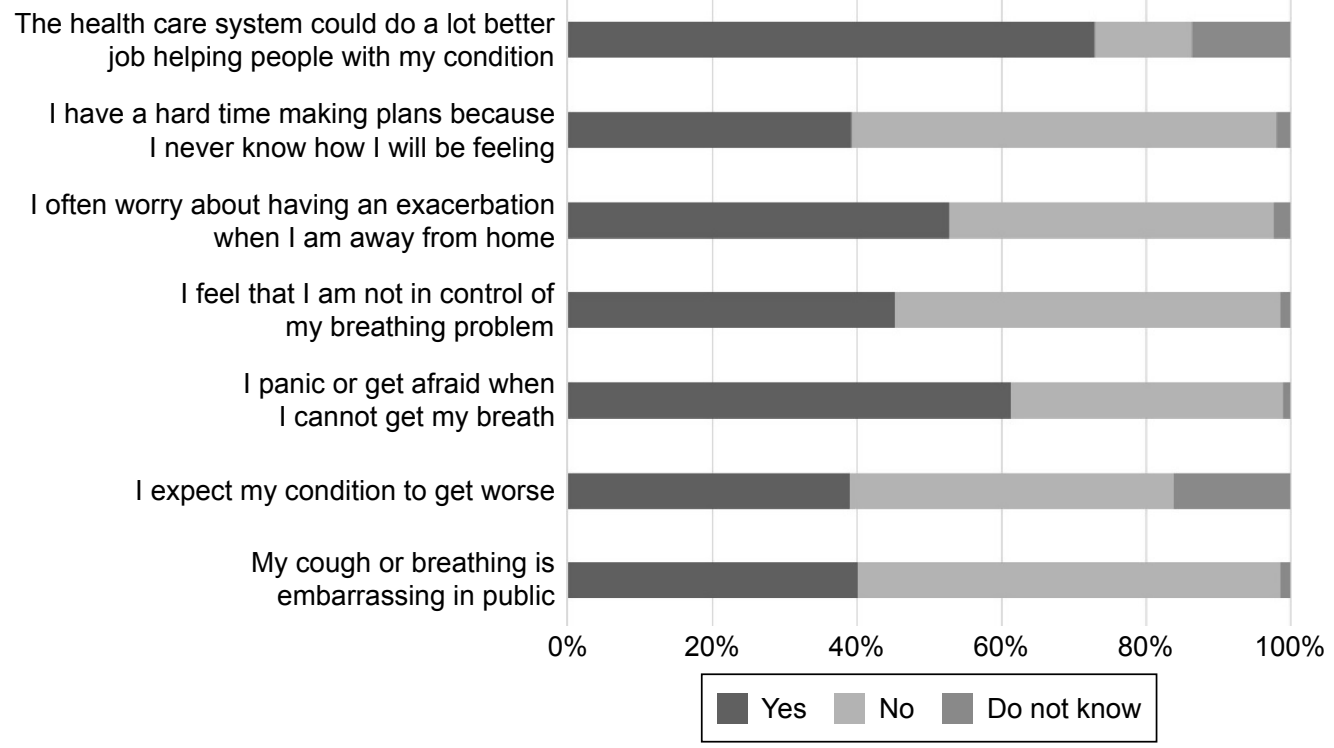

Figure 3 The psychological distress that patients with COPD have was also assessed.

Abbreviation: COPD, chronic obstructive pulmonary disease. 
The self-reported prevalence of COPD in Greece was estimated at $10.6 \%$, ranging from $5.5 \%$ in rural areas to $13.6 \%$ in urban areas. This estimation is marginally higher than that obtained 10 years ago from Tzanakis et al. ${ }^{14}$ In the previously conducted study, a prevalence of $8.4 \%$ had been estimated among patients aged $>35$ years. This difference in the prevalence estimations may indicate an actual increase in the number of subjects suffering from COPD during the last decade or may be attributed to methodological discrepancies between these two studies (mainly the exclusion of COPD patients with positive bronchodilator response in the former study), the difference in participants' characteristics (ie, participants' age), and the differences in the methods used (ie, telephone versus actual face-toface survey). Nonetheless, the potential increase of COPD prevalence in Greece is strongly supported by the findings of the Continuing to Confront COPD International Survey conducted in 2012-2013 in 12 countries. ${ }^{5}$ This study replicated the original Confronting COPD International Survey conducted in $2000^{8}$ and revealed an approximate absolute increase in COPD prevalence ranging from $1 \%$ (Italy, USA, Spain, and Germany) to 4\% (Japan) across the participating countries.

With respect to COPD patients' characteristics in Greece, it was found that there was a slight male predominance, in line with the international literature showing the higher prevalence of COPD in males. ${ }^{5,14,19}$ Asthma, hypertension, and diabetes were the three most commonly reported comorbidities and these findings are in alignment with the results of other studies. ${ }^{5,19}$ It should be acknowledged that although a significant percentage of COPD patients has also asthma-like symptoms and characteristics, the so-called asthma-COPD overlap syndrome, the percentage of asthma reported by our patients was excessively high. This rather represents a misperception of patients regarding the presence of asthma; a phenomenon that has also been observed in another similar telephone survey in the literature. ${ }^{5}$

Overall, only one-third (33.9\%) of participants in our study reported that their respiratory condition was of mild severity, a percentage very similar to that observed in the BREATH study $(31.7 \%)^{6}$ and in the two Confront COPD international surveys. ${ }^{5,8} \mathrm{On}$ the other hand, the percentage of patients perceiving a severe respiratory condition in our study (24.2\%) was similar to that observed in the International Surveys $\left(23 \%^{5}\right.$ and $\left.21 \%^{8}\right)$, but much higher than that in the BREATH study (10.4\%). ${ }^{6}$ The perceived severity was strongly correlated with the severity of breathlessness, the
CAT score, the history of exacerbations during the past year, and the GOLD category, indicating that patients are able to perceive the severity of their respiratory condition.

COPD had a significant impact on all daily activities ranging between $28 \%$ and $61.5 \%$ of subjects, which is consistent with the literature. ${ }^{6,8}$ Importantly, the results of our study indicate that COPD has a substantial impact on the working ability, given that almost one-fourth of the participants, among those in work, had missed work during the past 12 months with the mean number of days lost being 10 . Moreover, $\sim 40 \%$ of COPD patients reported reduced productivity for an average of 8 days, while $11 \%$ of participants reported that their respiratory condition had caused another member of their household to miss work in the previous year. These findings indicate that the impact of COPD on productivity in Greece is higher compared to that detected in Middle East and North Africa, ${ }^{6}$ where $21.5 \%$ of patients reported reduced productivity during some working days, $17.2 \%$ reported having missed work, and $8.1 \%$ reported that another member of the household missed work. The reason for these differences is not clear but it might relate to different levels disease severity between the studies and methodologies, although cultural, employment, and legal issues may also have played a role. Not surprisingly, the proportion of subjects reporting that they missed work or that the quality of their work was affected in the previous year due to their COPD was higher in subjects with higher disease severity, in those experiencing exacerbation of their symptoms, and in older patients. These results are aligned to those reported in the BREATH study. ${ }^{6}$ At this point, it should be highlighted that the impact of COPD on productivity loss would be even higher if we had taken into account the early retirement of patients in Greece.

Despite the relatively large size of the sample, the results of the present study may be affected by several methodological factors related to the study design. Above all, unlike the case of face-to-face survey, in a telephone survey, individuals without telephone service are automatically excluded. ${ }^{20,21}$ Moreover, several studies have shown that the response rate of telephone surveys is lower than that of face-to-face surveys, indicating that the former are vulnerable to a greater nonresponse bias that may affect the representativeness of the sample. ${ }^{20,22}$ The low response rate can also be attributed to the individuals' unwillingness to cooperate and engage in the interview, as well as the fact that telephone responders are more likely to express dissatisfaction with the length of the interview than face-to-face respondents, despite the fact that 
the telephone interviews are completed more quickly than the face-to-face interviews. ${ }^{21}$ Poor response quality may also occur in a telephone survey since responders can be tired from a long telephone conversation, do other things at the same time, or are suspicious of the interviewer. ${ }^{21}$ Moreover, the preexisting diagnosis of COPD was investigated by means of telephone interviews with no anthropometrical or spirometric measures. As such, all data are based on self-reports, indicating that the estimated prevalence might be underestimated, as happens in the majority of the epidemiological studies.

Finally, GOLD category and history of exacerbations during the past year were indirectly estimated based on the self-reported CAT score and worsening of specific symptoms. As such, the percentage of COPD patients experiencing exacerbations and the distribution of patients across GOLD categories should be cautiously interpreted. However, the impact of these two factors on social burden of COPD is in line with the findings of other studies using clinical examination and medical records to classify patients into GOLD category and into those with and without exacerbations.

\section{Conclusion}

The findings of the present study indicate that COPD affects slightly $>10 \%$ of the population aged $\geq 40$ years in Greece. Moreover, the present study provides unique data regarding the great impact of COPD on patients' everyday life and work. Greater investment in interventions aiming at delaying progression of disease, preventing acute exacerbations, and managing chronic symptoms may reduce the overall burden of COPD in Greece.

\section{Acknowledgment}

The authors would like to thank Hellenic Thoracic Society for scientific advices at study design and funding.

\section{Disclosure}

The authors report no conflicts of interest in this work.

\section{References}

1. Soriano JB, Rodriguez-Roisin R. Chronic obstructive pulmonary disease overview: epidemiology, risk factors, and clinical presentation. Proc Am Thorac Soc. 2011;8(4):363-367.

2. World Health Organization. The 10 leading causes of death in the world, 2000 and 2012. The top 10 causes of death; 2014. Available from: http:// www.who.int/mediacentre/factsheets/fs310/en/. Accessed March 7, 2016.

3. Murray CJ, Lopez AD. Alternative projections of mortality and disability by cause 1990-2020: Global Burden of Disease Study. Lancet. 1997;349(9064):1498-1504.
4. Shavelle RM, Paculdo DR, Kush SJ, Mannino DM, Strauss DJ. Life expectancy and years of life lost in chronic obstructive pulmonary disease: findings from the NHANES III Follow-up Study. Int J Chron Obstruct Pulmon Dis. 2009;4:137-148.

5. Landis SH, Muellerova H, Mannino DM, et al. Continuing to confront COPD international patient survey: methods, COPD prevalence, and disease burden in 2012-2013. Int J Chron Obstruct Pulmon Dis. 2014; 9:597-611.

6. Uzaslan E, Mahboub B, Beji M, et al. The burden of chronic obstructive pulmonary disease in the Middle East and North Africa: results of the BREATHE study. Respir Med. 2012;106(Suppl 2):S45-S59.

7. Polatli M, Ben Kheder A, Wali S, et al. Chronic obstructive pulmonary disease and associated healthcare resource consumption in the Middle East and North Africa: the BREATHE study. Respir Med. 2012;106(Suppl 2):S75-S85.

8. Rennard S, Decramer M, Calverley PM, et al. Impact of COPD in North America and Europe in 2000: subjects' perspective of Confronting COPD International Survey. Eur Respir J. 2002;20(4):799-805.

9. Hu J, Meek P. Health-related quality of life in individuals with chronic obstructive pulmonary disease. Heart Lung. 2005;34(6):415-422.

10. DiBonaventura M, Paulose-Ram R, Su J, et al. The burden of chronic obstructive pulmonary disease among employed adults. Int J Chron Obstruct Pulmon Dis. 2012;7:211-219.

11. Osman IM, Godden DJ, Friend JA, Legge JS, Douglas JG. Quality of life and hospital re-admission in patients with chronic obstructive pulmonary disease. Thorax. 1997;52(1):67-71.

12. Domingo-Salvany A, Lamarca R, Ferrer M, et al. Health-related quality of life and mortality in male patients with chronic obstructive pulmonary disease. Am J Respir Crit Care Med. 2002;166(5):680-685.

13. Joshi M, Joshi A, Bartter T. Symptom burden in chronic obstructive pulmonary disease and cancer. Curr Opin Pulm Med. 2012;18(2):97-103.

14. Tzanakis N, Anagnostopoulou U, Filaditaki V, Christaki P, Siafakas N. Prevalence of COPD in Greece. Chest. 2004;125(3):892-900.

15. Bestall JC, Paul EA, Garrod R, Garnham R, Jones PW, Wedzicha JA. Usefulness of the Medical Research Council (MRC) dyspnoea scale as a measure of disability in patients with chronic obstructive pulmonary disease. Thorax. 1999;54(7):581-586.

16. Jones PW, Harding G, Berry P, Wiklund I, Chen WH, Kline Leidy N. Development and first validation of the COPD Assessment Test. Eur Respir J. 2009;34(3):648-654.

17. Jones PW, Brusselle G, Dal Negro RW, et al. Properties of the COPD assessment test in a cross-sectional European study. Eur Respir J. 2011;38(1):29-35.

18. Global Initiative for Chronic Obstructive Lung Disease (GOLD). Global strategy for the diagnosis, management and prevention of COPD; 2011. Available from: http://www.goldcopd.org/

19. Fletcher MJ, Upton J, Taylor-Fishwick J, et al. COPD uncovered: an international survey on the impact of chronic obstructive pulmonary disease [COPD] on a working age population. BMC Public Health. 2011;11:612.

20. Weeks MF, Kulka RA, Lessler JT, Whitmore RW. Personal versus telephone surveys for collecting household health data at the local level. Am J Public Health. 1983;73(12):1389-1394.

21. Holbrook AL, Green MC, Krosnick JA. Telephone versus face-to-face interviewing of national probability samples with long questionnaires: comparisons of respondent satisficing and social desirability response bias. Public Opin Q. 2003;67(1):79-125.

22. Hox JJ, De Leeuw ED. A comparison of nonresponse in mail, telephone, and face-to-face surveys: applying multilevel modeling to metaanalysis. Qual Quant. 1994;28(4):329-344. 
International Journal of COPD

\section{Publish your work in this journal}

The International Journal of COPD is an international, peer-reviewed journal of therapeutics and pharmacology focusing on concise rapid reporting of clinical studies and reviews in COPD. Special focus is given to the pathophysiological processes underlying the disease, intervention programs, patient focused education, and self management protocols

\section{Dovepress}

This journal is indexed on PubMed Central, MedLine and CAS. The manuscript management system is completely online and includes a very quick and fair peer-review system, which is all easy to use. Visit $\mathrm{http}: / / \mathrm{www}$.dovepress.com/testimonials.php to read real quotes from published authors.

Submit your manuscript here: http://www.dovepress.com/international-journal-of-chronic-obstructive-pulmonary-disease-journal 